\title{
Co-ordinating meals and exercise for diabetes management
}

\author{
Elsamma Chacko ${ }^{1}$
}

Received: 9 March 2015 / Accepted: 17 March 2015 / Published online: 3 April 2015

(C) Springer-Verlag Berlin Heidelberg 2015

Keywords Breakfast $\cdot$ Diabetes $\cdot$ Exercise $\cdot$ Glucose control $\cdot$ Meal plan

To the Editor: In their recent article in Diabetologia [1], Jakubowicz and colleagues compared two meal plans: a high-energy breakfast and small supper vs a small breakfast and high-energy supper in type 2 diabetic patients. The results indicated reduced postprandial hyperglycaemia throughout the day with the meal plan featuring the high-energy breakfast. Kahleova and colleagues also reported that eating two meals a day, breakfast and lunch, is a better plan than eating six meals a day [2]. This is consistent with the finding that missing breakfast is associated with an increased risk of type 2 diabetes and worsening metabolic measures [3]. (The omission of breakfast means prolonging counter-regulation, and eating breakfast means switching to insulin action.) Taken together, these results can be seen as indicating that early switching of the hormone system from counter-regulation to insulin action and decreasing NEFA (and the resulting second-meal phenomenon) are important for diabetic patients [1]. A sensible meal plan for diabetic patients could involve distributing the total daily energy content among a big balanced breakfast, moderate lunch and a small supper. Such a meal plan offers favourable hormone levels, improved glucose profile and minimal hypoglycaemia risk $[1,2]$.

This moderate glucose profile can be further improved by timely post-meal exercise after the major meal—breakfast in

Elsamma Chacko

elsammac@msn.com

1 Connecticut Valley Hospital, PO Box 351, Silver Street, Middletown, CT 06457, USA this case. It has been known for more than three decades that a bout of light to moderate aerobic activity for up to $60 \mathrm{~min}$, starting $30 \mathrm{~min}$ after the first bite of a meal, can blunt the postmeal glucose peak $[4,5]$. This is because the bulk of the mealderived glucose is used up by the activity when glucose and insulin levels are high and counter-regulation is suppressed. Exercise before breakfast is known to increase glucose levels via endogenous glucose production [6]. There is also evidence that adding a short bout of resistance exercise before the aerobic activity, two or three times a week, improves physical fitness, body composition and $\mathrm{HbA}_{1 \mathrm{c}}$ [7].

A balanced breakfast followed by timely post-meal exercise could be a wise way to start the day for type 2 diabetic patients. Indications are that type 1 patients also could benefit from timely post-meal exercise after the main meal of the day [4]. Co-ordinating meals and exercise as described here would not violate current diabetes guidelines [8]. Long-term studies of the effect of such a lifestyle on $\mathrm{HbA}_{1 \mathrm{c}}$ and lipids would be useful.

Duality of interest The author declares that there is no duality of interest associated with this manuscript.

Contribution statement The author is the sole contributor to this paper.

\section{References}

1. Jakubowicz D, Wainstein J, Ahrēn B et al (2015) High-energy breakfast with low-energy dinner decreases overall daily hyperglycaemia in type 2 diabetic patients: a randomised clinical trial. Diabetologia. doi:10.1007/s00125-015-3524-9

2. Kahleova H, Belinova L, Malinska $H$ et al (2014) Eating two larger meals a day (breakfast and lunch) is more effective than six smaller meals in a reduced-energy regimen for patients with type 2 diabetes: a randomised crossover study. Diabetologia 57:1552-1560 
3. Mekary RA, Giovannucci E, Willett WC, van Dam RM, Hu FB (2012) Eating patterns and type 2 diabetes risk in men: breakfast omission, eating frequency, and snacking. Am J Clin Nutr 95:1182-1189

4. Nelson JD, Poussier P, Marliss EB, Albisser AM, Zinman B (1982) Metabolic response of normal man and insulin-infused diabetics to postprandial exercise. Am J Physiol 242:E309-E316

5. Colberg SR, Zarrabi L, Bennington L et al (2009) Post-prandial walking is better for lowering the glycemic effect of dinner than pre-dinner exercise in type 2 diabetic individuals. J Am Med Dir Assoc 10:394-397
6. Kjaer M, Hollenbeck CB, Frey-Hewitt B et al (1990) Glucoregulation and hormonal responses to maximal exercise in non-insulin-dependent diabetes. J Appl Physiol 68:2067-2074

7. Snowling NJ, Hopkins WJ (2006) Effects of different modes of exercise training on glucose control and risk factors for complications in type 2 diabetic patients. Diabetes Care 11: 2518-2527

8. American Diabetes Association (2015) Standards of medical care in diabetes - 2015: summary of revisions. Diabetes Care 38(Suppl 1):S4 